\title{
Pengaruh Inflasi, Indeks Pembangunan Manusia, Dan Upah Minimum Provinsi Terhadap Pengangguran Di Indonesia
}

\author{
Soeharjoto ${ }^{1}$, Mitha Rachma Oktavia ${ }^{2}$ \\ ${ }^{1}$ Universitas Trisakti, soeharjoto@trisakti.ac.id \\ ${ }^{2}$ Universitas Trisakti, rachmamitha@gmail.com
}

\begin{abstract}
Indonesia, which is part of Association of Southeast Asian Nations and Group of Twenty, participates in implementing sustainable economic development. There are still constraints in terms of macroeconomic development, such as employment which resulting in unemployment. This condition will affect the society and disrupt social and political stability. So it is necessary to conduct research related to unemployment.Purpose of this study is to analyze inflation effect, human development index, provincial minimum wage on unemployment in Indonesia. Used panel data regression method, with data from 33 provinces in Indonesia from 2015-2018. Unemployment is dependent variable with inflation, the human development index, and the provincial minimum wage as an independent variables. Accordance with the fixed effect model, results shown that inflation and human development index have a negative and significant effect on the unemployment in Indonesia, while the provincial minimum wage is not significant to the unemployment in Indonesia. To reducing unemployment, government can increasing their regions potentials, good regulations, and also society creativity and education.
\end{abstract}

Keywords: Human Development Index, Inflation, Provincial Minimum Wage, Unemployment

\begin{abstract}
ABSTRAK
Indonesia yang merupakan bagian dari Association of Southeast Asian Nations dan Group of Twenty turut serta melaksanakan pembangunan ekonomi yang berkelanjutan. Namun, dalam perkembangan makro ekonominya masih mengalami kendala pada penyerapan tenaga kerja, sehingga berdampak pada pengangguran. Kondisi ini, akan mempengaruhi kesejahteraan masyarakatnya yang pada akhirnya dapat mengakibatkan terganggunya stabilitas sosial dan politik. Untuk itu, perlu dilakukan penelitian yang berkaitan dengan pengangguran. Penelitian ini bertujuan untuk menganalisis pengaruh inflasi, indeks pembangunan manusia, dan upah minimum provinsi terhadap pengangguran di Indonesia. Metode yang digunakan regresi data panel, dengan data dari 33 provinsi di Indonesia pada 2015-2018. Pengangguran merupakan variabel terikat dengan variabel bebasnya berupa inflasi, indeks pembangunan manusia, dan upah minimum provinsi. Adapun hasilnya model yang sesuai fixed effect model, dengan perincian bahwa inflasi dan indeks pembangunan manusia berpengaruh secara negatif dan signifikan terhadap pengangguran di Indonesia, sedangkan upah minimum provinsi tidak signifikan terhadap pengangguran di Indonesia. Untuk itu, dalam mengurangi pengangguran pemerintah dapat meningkatkan potensi daerah, regulasi yang baik, serta ketrampilan dan pendidikan masyarakat.
\end{abstract}

Kata Kunci: Indeks Pembangunan Manusia, Inflasi, Pengangguran, Upah Minimum Provinsi

Naskah diterima: 04-05-2021, direvisi: 21-04-2021, diterbitkan: 01-06-2021

\section{PENDAHULUAN}

Kondisi makro ekonomi negara merupakan salah satu indikator keberhasilan pembangunan (Hariyanti \& Soeharjoto, 2020).
Untuk itu, setiap negara mengupayakan peningkatan pertumbuhan ekonomi dengan menerapkan pembangunan yang berkelanjutan (Soeharjoto \& Danova, 2020). Namun, makro 
ekonomi memiliki permasalahan besar terutama pada pengangguran (Astid \& Soekapdjo, 2020). Hal ini, telah membuat banyak negara mengalami ketimpangan distribusi pendapatan (Soeharjoto, 2020). Akan tetapi, untuk melakukan penanganannya sangat kompleks, sehingga banyak negara yang sulit keluar dari kemiskinan (Probosiwi, 2016). Dengan demikian, pengangguran perlu segera diatasi karena dapat mengganggu kondisi sosial dan politik (Prasetyoningrum $\&$ Sukmawati, 2018).

Indonesia sebagai negara yang berada di kawasan Asia Tenggara memiliki prospek ekonomi yang baik (Soekapdjo \& Esther, 2019). Hal ini, sesuai dengan pernyataan Amerika Serikat (AS) pada 10 Februari 2020, bahwa Indonesia sudah tidak terdaftar sebagai Developing and Least-Developed Countries (Idris, 2020). Indikator yang digunakan AS berdasarkan gabungan dari UNCTAD dan IMF-World Bank, serta menambahkan kriteria share perdagangan dunia dan keanggotaan pada organisasi kerja sama ekonomi internasional yakni OECD dan G20. Kebijakan yang ditetapkan AS, memberikan dampak positif berupa adanya pengakuan terhadap perekonomian Indonesia, tetapi dengan konsekuensi berupa hilangnya fasilitas kemudahan sebagai negara berkembang dalam melakukan ekspor. Adapun dampaknya, akan mengurangi daya saing yang akhirnya dapat mengakibatkan penurunan penggunaan tenaga kerja. Untuk itu, Indonesia perlu meningkatkan daya saing dengan meningkatkan sumber daya manusia agar dapat melakukan inovasi sehingga dapat menghasilkan produk yang berkualitas dan efisien.

Pertumbuhan ekonomi yang baik selama satu dekade di Indonesia secara perlahan dapat menurunkan angka pengangguran, tetapi dengan jumlah penduduk sekitar 260 juta jiwa, serta proporsi populasi penduduk yang siap masuk ke pasar tenaga kerja sekitar dua juta jiwa setiap tahunnya, merupakan tantangan yang besar bagi pemerintah. Apabila kondisi tersebut dapat dimanfaatkan secara optimal dengan adanya bonus demografi akan menjadi kekuatan besar bagi Indonesia untuk menjadi negara dengan perekonomian terbesar di Asia Tenggara.
Inflasi mengakibatkan harga semakin meningkat sehingga dapat menurunkan daya beli masyarakat (Ningsih \& Andiny, 2018). Untuk itu, produsen agar dapat bertahan di pasar perlu melakukan efisiensi dengan cara merampingkan organisasinya. Adapun dampaknya, akan mengurangi penggunaan tenaga kerja, sehingga akan terjadi peningkatan pengangguran.

Indeks pembangunan manusia (IPM) menggunakan tiga dimensi penting dalam meningkatkan pembangunan, yakni berupa aspek pemenuhan kebutuhan akan hidup sehat dan panjang usia, mendapatkan pengetahuan dan kemampuan memenuhi standar hidup yang layak (Muda, Koleangan, \& Kalangi, 2019). Jadi, dengan semakin baiknya tingkat kesehatan, pengetahuan dan penghidupan akan memberikan dampak pada peningkatan produktifitas dan kualitas kerja. Untuk itu, banyak negara yang mengupayakan adanya peningkatan IPM agar dapat mengurangi pengangguran.

Upah memiliki dua sisi yang penting yakni bagi pekerja dan perusahaan (Sulistiawati, 2012). Pekerja menganggap upah merupakan sumber penghasilan untuk memenuhi kebutuhannya yang berdampak pada adanya upaya dari pekerja meningkatkan pendapatannya, sedangkan perusahaan menganggap upah sebagai biaya yang harus dikeluarkan untuk keperluan produksi, sehingga dalam berproduksi perlu melakukan efisiensi dengan cara mengurangi biaya tenaga kerja. Adanya tuntutan pekerja dalam memperoleh upah yang semakin besar, akan berakibat semakin tingginya biaya produksi yang dapat meningkatkan harga produknya, sehingga akan berdampak pada penurunan permintaan konsumen dan akhirnya perusahaan akan mengurangi penggunaan tenaga kerja, agar perusahaan tetap efisien dan dapat bertahan di pasar. Hal ini, berakibat semakin meningkatnya pengangguran.

Indonesia dengan inflasi yang berfluktuasi namun masih dapat terkendali dan adanya penetapan UMP dengan pekerja yang memiliki IPM semakin meningkat akan mempengaruhi produktifitas dan efisiensi, sehingga diharapkan dapat peningkatan daya saing ekspornya, yang akhirnya akan meningkatkan penyerapan tenaga kerja. Untuk 
itu, perlu dilakukan penelitian pengaruh inflasi, IPM, dan UMP terhadap pengangguran di Indonesia.

\section{KAJIAN LITERATUR}

Pengangguran terdapat dalam setiap negara, terutama pada pengangguran normal, yang diakibatkan adanya masa transisi dari seseorang ketika meninggalkan pekerjaan lama dan belum menemukan pekerjaan yang baru, atau ketika baru lulus dari pendidikan dan sedang mencari pekerjaan (Mankiw, 2018). Pengangguran sendiri merupakan suatu kondisi dari seseorang yang masuk dalam angkatan kerja dan sedang mencari pekerjaan tetapi belum memperoleh pekerjaan (Todaro \& Smith, 2015). Jadi, pada prinsipnya manusia dalam menggunakan waktu dapat dibagi atas dua bagian, yakni waktu kerja dan senggang (Weiss, 2009). Untuk itu, manusia melakukan skala preferensi dalam penggunaan waktu. Kondisi ini, dalam kurva indiferensi yang menggambarkan kombinasi antara income dan leisure dengan tingkat kepuasan tertentu. Namun, dalam permintaan dan penawaran terhadap tenaga kerja akan berhubungan dengan upah, karena salah satu penyebab terjadinya pengangguran terutama dampak dari upah yang tidak fleksibel di pasar tenaga kerja (Kaufman \& Hotchkiss, 1999). Pada kondisi ekuilibrium akan terjadi full employment, tetapi dengan adanya resesi akan menyebabkan berkurangnya permintaan terhadap tenaga kerja (Patinkin, 1949).

Pertumbuhan penduduk dapat berkembang lebih pesat dibandingkan dengan pertumbuhan persediaan makanan (Malthus, 1798). Adapun maknanya adalah dengan semakin meningkatnya jumlah penduduk maka semakin meningkat jumlah tenaga kerja, tetapi tidak diimbangi dengan ketersediaan lapangan pekerjaan. Terbatasnya ketersediaan lapangan pekerjaan berakibat tenaga kerja akan bersaing dalam mendapatkan pekerjaan, sehingga ada yang tidak mendapatkan pekerjaan dan menjadi pengangguran.

Penelitian faktor-faktor yang mempengaruhi pengangguran di Indonesia sudah banyak dilakukan dengan hasil yang beragam. Hasil penelitian Putri (2015), mengungkapkan bahwa inflasi berpengaruh negatif terhadap pengangguran sedangkan penelitian dari Yanti, Anam, \& Adda (2017), menemukan bahwa inflasi tidak signifikan terhadap pengangguran. Penelitian Arizal \& Marwan (2019), dengan temuan bahwa IPM berpengaruh positif terhadap tingkat pengangguran, kemudian penelitian Mahroji \& Nurkhasanah (2019), dengan hasil bahwa IPM berpengaruh negatif terhadap pengangguran, sedangkan penelitian Latifah, Rotinsulu, \& Tumillar (2017) terungkap bahwa IPM tidak signifikan terhadap pengangguran. Penelitian dari Prawira (2018), terungkap bahwa UMP berpengaruh positif terhadap pengangguran dan penelitian Mahihody, Engka, \& Luntungan (2018), UMP berpengaruh negatif terhadap pengangguran, sedangkan hasilnya dari penelitian Hartanto \& Masjkuri (2017), diperoleh bahwa upah minimum tidak signifikan terhadap pengangguran.

\section{Kerangka Pemikiran}

Dari kajian teoritis dan penelitian terdahulu dapat dibuat kerangka pemikiran penelitian. Adapun kerangka penelitiannya digambarkan sebagai berikut:

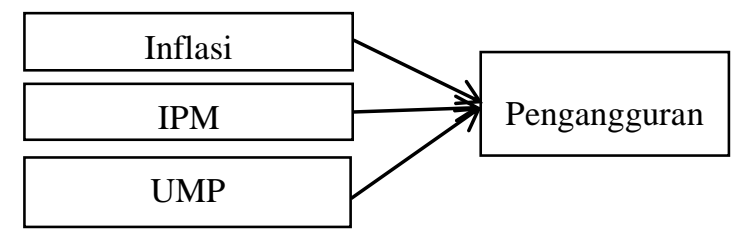

Gambar 1. Kerangka Pemikiran Penelitian

\section{METODE PENELITIAN}

Penelitian ini untuk mengetahui pengaruh inflasi, IPM, dan UMP terhadap tingkat pengangguran di Indonesia. Penelitiannya berupa kuantitatif dengan menggunakan metode regresi data panel. Data dari Badan Pusat Statistik (BPS) dengan menggunakan data cross section dari 33 provinsi di Indonesia dan time series pada 2015-2018. Untuk variabel terikatnya berupa pengangguran dan variabel bebasnya menggunakan inflasi, IPM, dan UMP. Adapun model yang digunakan adalah sebagai berikut:

$$
\mathrm{TPT}_{\mathrm{it}}=\beta_{0}+\beta_{1} \mathrm{INF}_{\mathrm{it}}+\beta_{2} \mathrm{IPM}_{\mathrm{it}}+\beta_{3} \mathrm{UMP}_{\mathrm{it}}+\mathrm{e}_{\mathrm{it}} \ldots \text { (1) }
$$

Keterangan:

TPT :Tingkat Pengangguran Terbuka.

INF :Inflasi. 
IPM :Indeks Pembangunan Manusia.

UMP :Upah Minimum Provinsi.

\section{Hubungan Inflasi dengan Pengangguran}

Keterkaitan antara inflasi dengan pengangguran dapat dijelaskan dalam kurva Phillips, yang menyatakan bahwa pada tingkat pengangguran yang rendah cenderung disertai oleh inflasi yang tinggi dan saat pengangguran tinggi cenderung disertai dengan inflasi yang rendah (Samuelson \& Nordhaus, 2010). Hubungan antara inflasi dengan tingkat pengangguran didasarkan pada asumsi bahwa inflasi merupakan cerminan dari adanya kenaikan permintaan agregat. Adanya kenaikan permintaan agregat sesuai dengan teori permintaan bahwa adanya permintaan yang naik akan mengakibatkan harga juga naik. Pada saat inflasi, dalam memenuhi permintaan tersebut, produsen akan meningkatkan kapasitas produksinya, dengan cara menambah tenaga kerja. Dengan demikian, peningkatan permintaan tenaga kerja yang disebabkan oleh naiknya harga akan mengakibatkan pengangguran menjadi berkurang. Keadaan ini, sesuai dengan hasil penelitian yang dilakukan Putri (2015), bahwa inflasi berpengaruh negatif terhadap pengangguran terdidik. Penelitian Firdhania, \& Muslihatinningsih (2017), dengan hasil bahwa inflasi berpengaruh negatif terhadap pengangguran di Kabupaten Jember. Untuk itu, dapat dibuat hipotesa bahwa $\mathrm{H}_{1}$ : Inflasi berpengaruh negatif dan signifikan terhadap pengangguran di Indonesia.

\section{Hubungan IPM dengan Pengangguran}

Menurut teori pertumbuhan baru menekankan bahwa pemerintah mempunyai peranan dalam meningkatkan pembangunan human capital dan pengembangan untuk meningkatkan produktifitas manusia (Anwar, 2017). Dengan demikian, diharapkan investasi pendidikan akan mampu meningkatkan kualitas sumber daya manusia yang ditunjukkan dengan meningkatnya pengetahuan dan keterampilan seseorang. Jadi, semakin tinggi kualitas manusia akan semakin meningkat pula pengetahuan dan keahliannya, sehingga akan mendorong meningkatnya produktifitas. Hal tersebut, akan membuat perusahaan memperoleh profit yang lebih tinggi, sehingga semakin banyak tenaga kerja yang dapat terserap dan akhirnya akan menurunkan tingkat pengangguran. Keadaan ini, sesuai dengan hasil penelitian dari Mahroji \& Nurkhasanah (2019), bahwa IPM berpengaruh negatif terhadap pengangguran di Provinsi Banten. Penelitian yang dilakukan Astrid, \& Soekapdjo (2020), dengan temuan bahwa IPM berpengaruh negatif terhadap pengangguran di Indonesia. Untuk itu, dapat dibuat hipotesa bahwa $\mathrm{H}_{2}$ : IPM berpengaruh negatif dan signifikan terhadap tingkat pengangguran di Indonesia.

\section{Hubungan UMP dengan Pengangguran}

Kebijakan UMP, diterapkan atas dasar pertimbangan untuk meningkatkan kesejahteraan masyarakat, terutama golongan masyarakat yang berada di bawah garis kemiskinan. Dengan meningkatnya upah minimum, diharapkan mampu meningkatkan pendapatan pekerja, sehingga dapat memenuhi kebutuhan hidupnya. Upah minimum dapat mencegah pekerja tereksploitasi, terutama yang memiliki low skilled. Upah minimum dapat meningkatkan dan menurunkan penawaran tenaga kerja (Mansur, Engka, \& Tumangkeng, 2014). Penetapan upah minimum yang dilakukan oleh pemerintah pada suatu wilayah akan memberikan pengaruh terhadap besarnya tingkat pengangguran pada wilayah tersebut. Oleh karena itu, semakin tinggi upah minimum yang ditetapkan akan membawa pengaruh pada tingginya tingkat pengangguran yang terjadi (Kaufman \& Hotchkiss, 1999). Hal tersebut, dapat terjadi karena dengan semakin meningkatnya upah yang ditetapkan akan berpengaruh pada peningkatan penawaran tenaga kerja dan biaya produksi yang harus dikeluarkan oleh perusahaan. Akibatnya, perusahaan akan melakukan efisiensi dengan cara mengurangi jumlah tenaga kerjanya. Keadaan ini, sesuai dengan hasil penelitian dari Prawira (2018), bahwa UMP berpengaruh positif terhadap pengangguran di Indonesia. Penelitian Helvira, \& Rizki (2020), dengan temuan bahwa UMP berpengaruh positif terhadap pengangguran di Provinsi Kalimantan Barat. Untuk itu, dapat dibuat hipotesa bahwa $\mathrm{H}_{3}$ : UMP berpengaruh positif dan signifikan terhadap tingkat pengangguran di Indonesia. 


\section{PEMBAHASAN}

Pengangguran di Indonesia pada 2011-2018 memiliki tren yang berfluktuatif dengan kecenderungan menurun. Pada 2011 merupakan pengangguran tertinggi sebesar 7,48 persen, tetapi setelah itu pengangguran mengalami penurunan. Pada 2013 dan 2015 pengangguran mengalami peningkatan lagi menjadi 6,17 persen dan 6,28 persen, yang dikarenakan adanya peningkatan angkatan kerja tetapi tidak diimbangi dengan ketersediaan lapangan pekerjaan.

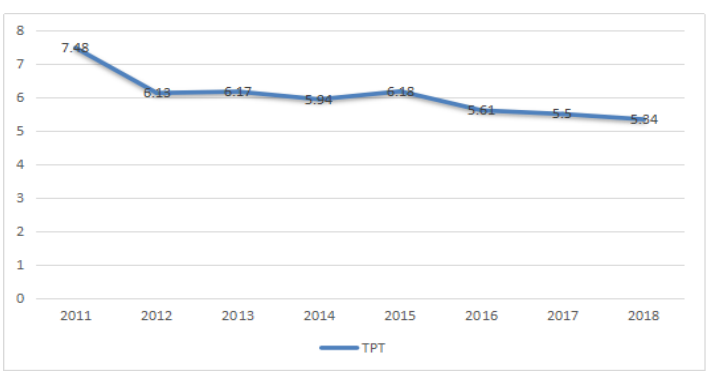

Sumber : BPS, 2020.

Gambar 2. TPT di Indonesia Pada 2011-2018 (Persen)

Perkembangan inflasi di Indonesia mengalami fluktuasi selama 2011-2018. Pada 2011-2013 memiliki tren yang meningkat secara ekstrim, dengan peningkatan sebesar 4,58 persen pada 2012-2013. Inflasi yang tinggi ini terjadi karena dampak dari adanya kenaikan harga BBM menjelang hari raya Idul Fitri dan kebijakan pengurangan impor. Namun, pada 2013-2016 memiliki tren yang menurun dengan kondisi terekstrim pada 2014-2015 terjadi penurunan sebesar 5,51 persen. Pada 2016-2018 inflasi bergejolak sedikit dengan rata-rata sebesar 4,18 persen.

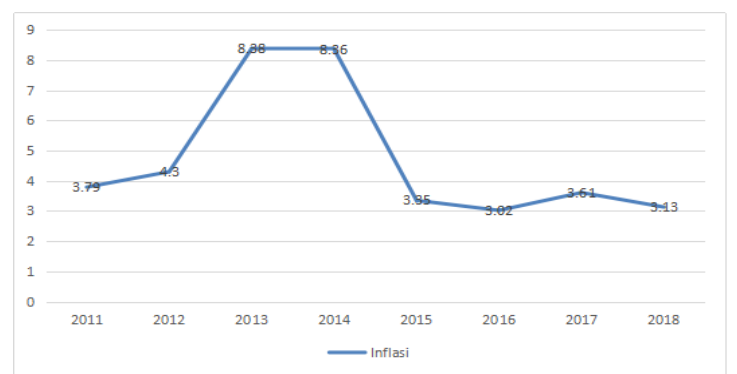

Sumber: BPS, 2020.

Gambar 3. Inflasi di Indonesia Pada 2011-2018 (Persen)

IPM di Indonesia memiliki tren yang terus meningkat. Pada 2011-2015 nilai IPM berada di bawah 70 dan masuk dalam kategori sedang, kemudian pada 2016-2018 nilai IPMnya meningkat lagi menjadi di atas 70 . Hal ini menandakan kualitas sumber daya manusia di Indonesia mengalami kemajuan dengan perkembangan yang signifikan. Namun, tetap terdapat permasalahan terutama pada peningkatan IPM yang tidak dapat diikuti dengan kecepatan penurunan pengangguran.



Sumber: BPS, 2020.

Gambar 4. IPM di Indonesia Pada 2011-2018

UMP di Indonesia pada 2011-2018 mengalami tren meningkat dengan rata-rata pertumbuhan UMP sebesar 12,67 persen. Adapun penyebabnya karena semakin meningkatnya harga dan kebutuhan hidup masyarakat. Hal ini, berakibat pekerja menginginkan adanya kenaikan upah. Untuk itu, pemerintah sebagai fasilitator antara pekerja dan pengusaha berupaya untuk dapat menetapkan UMP yang sesuai dengan keinginan pekerja dan kemampuan pengusaha. Untuk itu, pengusaha tetap diberikan ruang agar tetap berinvestasi di wilayah tersebut guna menyerap tenaga kerja yang ada.

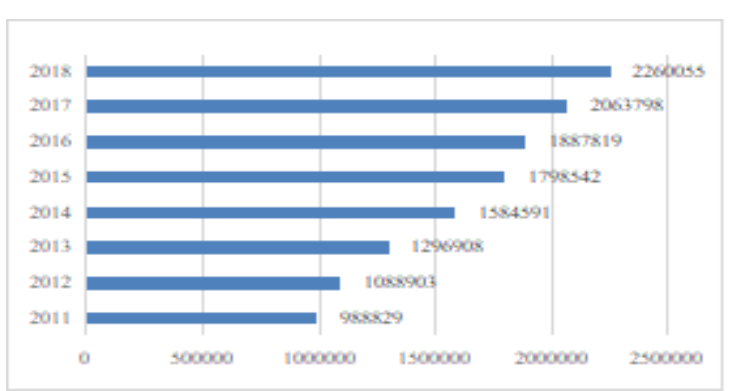

Sumber: BPS, 2020

Gambar 5. UMP di Indonesia Pada 2011-2018 (Rupiah)

\section{Hasil Estimasi Model Data Panel}

Hasil dari Chow test diperoleh nilai probabilitas Chi-square sebesar $0,0000<0,05$ dan Hausman test dengan nilai probabilitas 
Chi-square sebesar $0,0004<0,05$. Hal ini, berarti dapat disimpulkan bahwa dari hasil Chow test dan Hausman test model yang terbaik untuk digunakan adalah fixed effect model. Berdasarkan hasil nilai probabilitas Fstatistik pada model ini bernilai $0,0000<0,05$, yang artinya dari inflasi, IPM, dan UMP minimal terdapat satu variabel yang berpengaruh terhadap pengangguran di Indonesia. Uji koefisien determinasi (Adj $R$ Square) diperoleh sebesar 89,44 persen, yang artinya inflasi, IPM, dan UMP dapat menjelaskan terhadap pengangguran sebesar 89,44 persen sedangkan sisanya yang 10,56 persen dipengaruhi oleh variabel lain di luar model.

Tabel 1. Hasil Pengujian

\begin{tabular}{lcc}
\hline \multicolumn{1}{c}{ Variable } & Coefficient & Prob. \\
\hline C & 24.69407 & 0.0000 \\
\hline INF & -0.005148 & 0.0446 \\
\hline IPM & -5.450613 & 0.0000 \\
\hline UMP & 0.000302 & 0.9024 \\
\hline R-Squared & & \\
\hline Adj R-Squared & 0.9226 & \\
& & \\
\hline Prob(F-statistic) & \multicolumn{2}{c}{0.8944} \\
\end{tabular}

Sumber: Hasil data olahan penelitian, 2020.

Inflasi memiliki koefisien sebesar minus 0,005148 dengan nilai probabilitas sebesar $0,0446<05$, yang artinya inflasi berpengaruh negatif dan signifikan terhadap pengangguran di Indonesia. Jadi, meningkatnya inflasi akan menurunkan pengangguran di Indonesia dan sebaliknya, menurunnya inflasi akan meningkatkan pengangguran di Indonesia. Kondisi yang terjadi sesuai dengan teori Phillips yang mengatakan bahwa apabila inflasi naik maka akan menurunkan tingkat pengangguran. Hasil dari penelitiannya sama dengan penelitian Putri (2015), yang mengungkapkan bahwa inflasi berpengaruh negatif terhadap pengangguran.

Indeks pembangunan manusia memiliki koefisien sebesar minus 5,450613 dengan nilai probabilitas sebesar $0,0000<$ 0,05 , yang artinya IPM berpengaruh negatif dan signifikan terhadap pengangguran di
Indonesia. Adanya peningkatan IPM akan menurunkan pengangguran di Indonesia dan sebaliknya, menurunnya IPM akan meningkatkan pengangguran di Indonesia. Keadaan ini sesuai dengan teori pertumbuhan baru yang berpendapat bahwa indeks pembangunan manusia memiliki pengaruh terhadap tingkat pengangguran. Hasil penelitian ini sama dengan penelitian Mahroji \& Nurkhasanah (2019) yang menyatakan bahwa indeks pembangunan manusia berpengaruh negatif terhadap pengangguran.

UMP memiliki koefisien sebesar 0.000302 dengan nilai probabilitas sebesar $0,9024>0,05$, sehingga UMP tidak signifikan terhadap pengangguran di Indonesia. Hal ini, tidak sesuai dengan hasil penelitian Prawira (2018), yang mengungkapkan bahwa UMP berpengaruh positif terhadap pengangguran. Akan tetapi, hasilnya sesuai dengan penelitian Hartanto \& Masjkuri (2017), yang menyatakan bahwa upah minimum tidak signifikan terhadap pengangguran. Hasil penelitian ini mengindikasikan bahwa kebijakan UMP merupakan instrumen yang diterapkan pemerintah dalam upaya untuk meningkatkan kesejahteraan masyarakat. Namun, adanya UMP akan menjadi kendala bagi perusahaan untuk meningkatkan efisiensi agar tetap memiliki daya saing. Untuk itu, dalam penetapan UMP pemerintah juga mempertimbangkan kemampuan dari perusahaan. Dengan demikian, adanya kesepakatan antara pemerintah dan pengusaha dalam penetapan UMP tidak menciptakan peningkatan harga tenaga kerja secara signifikan, sehingga tidak menciptakan kondisi penawaran tenaga kerja melebihi permintaannya yang dapat meningkatkan pengangguran. Disamping itu, kebijakan ini juga tidak menciptakan terjadinya penurunan penyerapan tenaga kerja akibat tidak sebandingnya antara pertumbuhan tenaga kerja dengan penyerapan tenaga kerja.

Dari ketiga puluh tiga provinsi yang ada, terdapat tiga provinsi di Indonesia yang memiliki banyak pengangguran, yakni Jakarta, Kalimantan Timur, dan Banten. Tingginya pengangguran di Jakarta karena sebagai ibu kota dengan populasi penduduk yang padat mengakibatkan persaingannya semakin ketat, sehingga banyak tenaga kerja yang tidak dapat terserap di pasar. 
Peningkatan pengangguran di Kalimantan Timur terjadi akibat dampak dari krisis ekonomi global yang mengakibatkan jatuhnya sektor pertambangan batu bara dan migas yang mengakibatkan banyaknya pemberhentian hubungan kerja (PHK). Provinsi Banten memiliki pengangguran yang tinggi akibat adanya tuntutan kenaikan upah minimum yang tinggi tetapi tidak diikuti dengan peningkatan produktifitas yang mengakibatkan perusahaan menjadi tidak efisien, sehingga terjadinya tren dari industri padat karya melakukan relokasi usahanya ke wilayah lain. Untuk itu, dalam mengatasi pengangguran yang terjadi, pemerintah dapat meningkatkan potensi daerah, regulasi yang baik, serta ketrampilan dan pendidikan masyarakat.

\section{SIMPULAN}

Penelitian determinasi pengangguran di Indonesia menggunakan metode regresi data panel dari 33 provinsi pada 2015-2018, dengan model yang sesuai fixed effect model. Adapun hasilnya inflasi dan IPM berpengaruh negatif dan signifikan terhadap pengangguran di Indonesia. Namun, UMP tidak signifikan terhadap pengangguran di Indonesia. Fenomena ini, mengungkapkan bahwa pengangguran di Indonesia yang disebabkan inflasi dan IPM sesuai dengan kurva Philips dan teori pertumbuhan baru. Untuk itu, dalam penelitian selanjutnya perlu menggunakan pengangguran berdasarkan tingkat pendidikan dan menggunakan indeks kebutuhan hidup minimum, agar dapat diketahui kluster penganggurannya, sehingga akan mempermudah penanggulangannya.

\section{REFERENSI}

Anwar, A. (2017). Peran Modal Manusia terhadap Pertumbuhan Ekonomi Regional di Jawa. Jurnal Economia, 13(1), 79-94. https://doi.org/http://dx.doi.org/10.21831 /economia.v13i1.13323

Arizal, M., \& Marwan. (2019). Pengaruh Produk Domestik Regional Bruto dan Indeks Pembangunan Manusia terhadap Tingkat Pengangguran Terbuka di Provinsi Sumatera Barat. Jurnal Ecogen, 2(3), https://doi.org/http://dx.doi.org/10.24036 /jmpe.v2i3.7414

Astid, E., \& Soekapdjo, S. (2020). Pengaruh Inflasi, Jumlah Penduduk, IPM, PMA, dan PMDN terhadap Tingkat Pengangguran di Indonesia. Forum Ekonomi, 22(2), 319-325. https://doi.org/http://dx.doi.org/10.29264 /jfor.v22i2.7343

Firdhania, R., \& Muslihatinningsih, F. (2017), Faktor-faktor yang Mempengaruhi Tingkat Pengangguran di Kabupaten Jember. e-Journal Ekonomi Bisnis dan Akuntansi, 4(1). 117-121. https://doi.org/10.19184/ejeba.v4i1.474

Hariyanti, D., \& Soeharjoto. (2020). Pengaruh Ekonomi Global dan Domestik Terhadap Inflasi di Indonesia. Ekonika: Jurnal Ekonomi Universitas Kadiri, 5(1), 64-76.

https://doi.org/http://dx.doi.org/10.30737 /ekonika.v5i1.453

Hartanto, T. B., \& Masjkuri, S. U. (2017). Analisis Pengaruh Jumlah Penduduk, Pendidikan, Upah Minimum dan Produk Domestik Regional Bruto (PDRB) terhadap Jumlah Pengangguran di Kabupaten dan Kota Provinsi Jawa Timur Tahun 2010-2014. Jurnal Ilmu Ekonomi Terapan, 2(1), 1-11. https://doi.org/http://dx.doi.org/10.20473 /jiet.v2i1.5502

Helvira, R. \& Rizki, E.P. (2020). Pengaruh Investasi, Upah Minimum dan IPM Terhadap Tingkat Pengangguran Terbuka di Provinsi Kalimantan Barat. JIsEB, 1(1) 54-62.

Idris, M. (2020). Maksud Terselubung AS Memasukkan RI sebagai Negara Maju. Kompas. Repéré à https://money.kompas.com/read/2020/02 /22/104551926/maksud-terselubung-asmemasukkan-ri-sebagai-negaramaju?page $=$ all

Kaufman, B., \& Hotchkiss, J. L. (1999). The Economics of Labor Markets (Fifth Edition). Georgia: The Dryden Press.

Latifah, N., Rotinsulu, D. C., \& Tumillar, R. L. (2017). Pengaruh Pertumbuhan Ekonomi dan Indeks Pembangunan Manusia terhadap Tingkat Pengangguran Terbuka dan Dampaknya Pada Jumlah 
Penduduk Miskin di Kota Manado. Jurnal Berkala Ilmiah Efisiensi, 17(02), 106-117.

Mahihody, A. Y., Engka, D. S. M., \& Luntungan, A. Y. (2018). Pengaruh Upah dan Indeks Pembangunan Manusia (IPM) terhadap Pengangguran di Kota Manado. Jurnal Berkala Ilmiah Efisiensi, 18(3), 24-34.

Mahroji, D., \& Nurkhasanah, I. (2019). Pengaruh Indeks Pembangunan Manusia terhadap Tingkat Pengangguran di Provinsi Banten. Jurnal Ekonomi-Qu, 9(1), 51-72. https://doi.org/http://dx.doi.org/10.35448 /jequ.v9i1.5436

Malthus, T. R. (1798). An Essay on the Principle of Population. London: $\mathrm{J}$. Jhonson.

Mankiw, N. G. (2018). Macroeconomics (Tenth Edit). US: Macmillan International Higher Education.

Mansur, N., Engka, D., \& Tumangkeng, S. (2014). Analisis Upah terhadap Pengaangguran di Kota Manado Tahun 2003-2012. Jurnal Berkala Ilmiah Efisiensi, 14(2), 14-28. Repéré à https://ejournal.unsrat.ac.id/index.php/jbi e/article/view/4182/3711

Muda, R., Koleangan, R., \& Kalangi, J. B. (2019). Pengaruh Angka Harapan Hidup, Tingkat Pendidikan Dan Pengeluaran Perkapita Terhadap Pertumbuhan Ekonomi Di Sulawesi Utara Pada Tahun 2003-2017. Jurnal Berkala Ilmiah Efisiensi, 19(1), 44-55.

Ningsih, D., \& Andiny, P. (2018). Analisis Pengaruh Inflasi dan Pertumbuhan Ekonomi terhadap Kemiskinan Indonesia. Jurnal Samudra Ekonomika, 2(1), 53-61. https://doi.org/https://doi.org/10.1234/jse .v2i1.777

Patinkin, D. (1949). Involuntary Unemployment and the Keynesian Supply Function. The Economic Journal, 59(235),

360-383.

https://doi.org/https://doi.org/10.2307/22 26869

Prasetyoningrum, A. K., \& Sukmawati, U. S. (2018). Analisis Pengaruh Indeks Pembangunan Manusia (IPM), Pertumbuhan Ekonomi, dan
Pengangguran terhadap Kemiskinan di Indonesia. Equilibrium: Jurnal Ekonomi Syariah, 6(2), 217-240. https://doi.org/10.21043/equilibrium.v6i 2.3663

Prawira, S. (2018). Pengaruh Pertumbuhan Ekonomi, Upah Minimum Provinsi, dan Tingkat Pendidikan terhadap Pengangguran Terbuka di Indonesia. Jurnal Ecogen, 1(1), 162-168. https://doi.org/10.24036/jmpe.v1i1.4735

Probosiwi, R. (2016). Pengangguran dan Pengaruhnya terhadap Tingkat Kemiskinan. Jurnal Penelitian Kesejahteraan Sosial, 15(2), 89-100.

Putri, Rizka F. (2015). Analisis Pengaruh Inflasi, Pertumbuhan Ekonomi dan Upah terhadap Pengangguran Terdidik. Economics Development Analysis Journal, $\quad 4(2), \quad 175-181$. https://doi.org/https://doi.org/10.15294/e daj.v4i2.14821

Samuelson, P. A., \& Nordhaus, W. D. (2010). Economics (19 Edition). Boston: McGraw Hill.

Soeharjoto. (2020). Factors That Affect Inequality Distribution Income in Central Java. International Journal of Economics, Business and Accounting Research (IJEBAR), 4(3), 122-130. https://doi.org/https://doi.org/10.29040/ij ebar.v4i03.1196

Soeharjoto, \& Danova, G. K. (2020). Pengaruh Makro Ekonomi terhadap Cadangan Devisa di Asean-5. Jurnal Ecodemica, 4(1), 68-76. https://doi.org/https://doi.org/10.31294/j eco.v4i1.7732

Soekapdjo, S., \& Esther, A. M. (2019). Determinasi Pertumbuhan Ekonomi Berkelanjutan di Asean-3. Jurnal Ilmiah Ekonomi Dan Bisnis, 16(2), 176-182. https://doi.org/https://doi.org/10.31849/ji eb.v16i2.2978

Sulistiawati, R. (2012). Pengaruh Upah Minimum terhadap Penyerapan Tenaga Kerja dan Kesejahteraan Masyarakat di Provinsi di Indonesia. Jurnal Eksos, 8(3), 195-211.

Todaro, M. P., \& Smith, S. C. (2015). Economic Development. Harlow: Pearson.

Weiss, Y. (2009). Work and Leisure: A 
history of Ideas. Journal of Labor

Economics, 27(1), 1-20.

https://doi.org/https://doi.org/10.1086/59

6993

Yanti, N. F., Anam, H., \& Adda, H. W. (2017). Analisis Pengaruh Inflasi, Investasi dan PDRB terhadap Tingkat Pengangguran di Wilayah Sulawesi Periode 2010-2014. e Jurnal Katalogis, 5(4), 138-149. 